Authenticity, transition and mathematical competence: An exploration of the values and ideology underpinning an increase in the amount of mathematics in the science curriculum in England.

Victoria Wong

University of Oxford, Department of Education, 15 Norham Gardens, OX2 6PY

Vicky.wong@education.ox.ac.uk 


\title{
Authenticity, transition and mathematical competence: An exploration of the values and ideology underpinning an increase in the amount of mathematics in the science curriculum in England.
}

\begin{abstract}
Science is a much-revised and contested area of the curriculum. A new curriculum has recently been introduced in England which includes far more mathematical aspects of science than previous versions. This study asks what the influences, ideologies and values are which led to this change. A two-phase qualitative approach was followed comprising an analysis of government and other influential documentation together with-semi-structured interviews with key contributors to the science and mathematics education discourse together with an analysis of government and other influential documentation. This study is unusual both in its focus on those who were responsible for making science education policy and its focus on the policy development of the mathematical aspects of the science curriculum. The findings suggest that drivers for increasing the amount of mathematics in science include concerns about standards, the difficulties students have transitioning to higher stages of science education and the desire to improve students' broader mathematical competence. Aiming to improve students' mathematical competence is an aim for all students. In contrast, helping students transition to further scientific study is for a minority. I argue that ideologies and values which underpin the curriculum need to be interrogated more closely and should remain a focus of research.
\end{abstract}

Key words: mathematics; policy; interview; STEM

\section{Introduction and background}

Donnelly (2006) suggests that in England one could argue that science is the most revised area of the national curriculum. Fensham agrees and further submits that this is often the case internationally with science one of the most contested components of the school curriculum with 'multiple stakeholders presenting demands' (2009, p. 1080). Changes to the curriculum, he argues, often reflect shifting influence of those stakeholders. Fensham (2009) and Ryder (2015) both argue that the formation of science education policy, together with the political and cultural context of that formation, is often ignored in science education research. Consequently, the contested nature of science in the curriculum is frequently disregarded. This study aims to fill that gap through exploring the development of the most recent (2015) science curriculum in England. Fensham (2009) argues that education policies are operational statements of values, and that in any discussion of policy one should consider whose values about science education are favoured and which groups in society will be advantaged and which disadvantaged by the science education practices that flow from the policy.

As science is itself dynamic and continually changing, reform is necessary to ensure the content of the curriculum reflects current scientific thinking. Beyond this, however, science curriculum reforms have often involved significant changes in how science is presented or the scope of science as a subject (Ryder, 2015), for example by emphasising the social impacts of science or the nature or history of science. These impacts can have significant impacts for teachers and students in classrooms, although Ryder further argues that what those designing the curriculum intend is rarely what actually occurs as a result of the reform. 
These curriculum changes are not unique to England. Hollins and Reiss (2016), in a study of science curriculum content in 11 high performing jurisdictions, found that most were undergoing reform of some kind.

\begin{abstract}
The term policy is commonly used but diffieult to define (Hill, 2013). Ballstorgests policy is

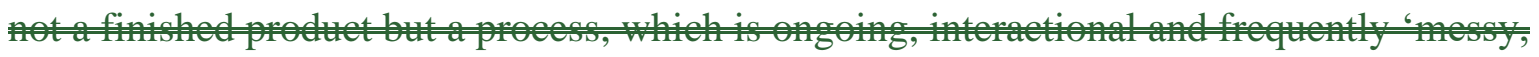
eonalie y, eonfuce and unelear' $(2013, \mathrm{p} .8)$. In this paper, I ask what the influenees; ideologies and values are behind a panticular policy, namely signifieantly inereasing the

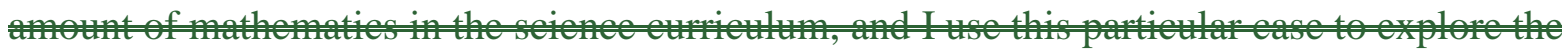
strugres and eontested nature of senee in the eurrieulum.

Iuse Hill's on of ideogy:

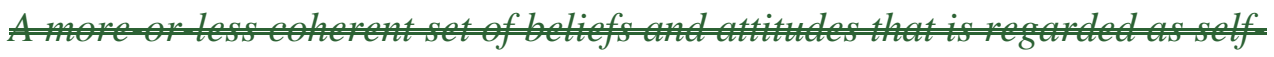

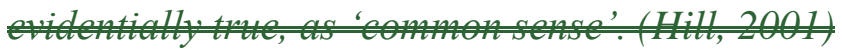

And dra on Halstead's definition of values:

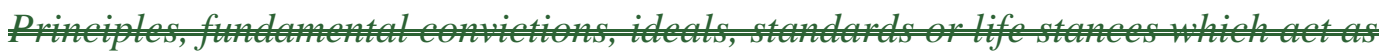

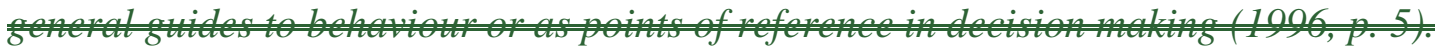

\title{
Science in the English national curriculum - a brief history
}

In England there has been limited change to the national curriculum for mathematics since it was first written (Wong, 2018). By contrast, in science debates about the nature and emphasis of the subject continue, as evidenced in the very different visions of science which are presented in the three most recent versions of the secondary science national curriculum: 2004 (DfE and QCA, 2004), 2006 (QCA, 2006) and 2015 (DfE, 2015).

The widely cited Beyond 2000 report (Millar \& Osborne, 1998) identified three distinct aims for science education: enhancing student interest in science by promoting wonder and curiosity; supporting the development of 'scientific literacy' for all students; and the preparation for further scientific study. The bulk of the report focused on improving scientific literacy. While these aims can be identified to a greater or lesser extent in all the national curricula which followed, the multiple - and disparate - aims create tensions in what is to be prioritised. Ryder and Banner (2011) argue that of Beyond 2000's three identified aims for the science curriculum, enhancing interest and improving scientific literacy are aims for all students, while providing the start of a scientific career is clearly only an aim for a few.

The most prominently stated aim of the 2004 curriculum was to encourage more students to study more science (DfE and QCA, 2004), prioritising, therefore, the aim for the few.

In 2006 the curriculum changed again, although only for 14-16s. This is the least prescriptive of the national curricula for science in England, consisting of a single page of text, half of which is devoted to 'How Science Works' or scientific literacy (QCA, 2006). Details of scientific content are therefore much sparser and Ryder and Banner argue that the 'demands of subject maintenance are less visible' (2011, p. 720). They suggest that traditionally the stakeholders who have argued for the prominence and identity of the separate sciences are professional scientists, who were not central players in the development activities which led to this particular curriculum. They identify this reduction in visibility with a shift in ownership of the science curriculum away from professional scientists, with the prominent 
stakeholders for the 2006 curriculum being university-based science education researchers. They suggest this shift is probably due to the influence of the Beyond 2000 report.

In England, the interests of the professional scientists as stakeholders in the curriculum are usually channelled through the Learned Societies. Working together as SCORE (the Science COmmunity Representing Education, based at the Royal Society), the Learned Societies (including the Royal Society, the Royal Society of Chemistry, the Royal Society of Biology and the Institute of Physics) had considerable impact on the development of the 2015 curriculum, with multiple drafts being commented on by education departments of each society (pers. comm.). Some of the comments on these drafts are available publically on the SCORE website (SCORE, 2014). In the 2015 curriculum the first aim of the curriculum is stated as: 'enabling students to develop scientific knowledge and conceptual understanding through the specific disciplines of biology, chemistry and physics' (DfE, 2015, p. 5). This aim, together with the much greater specificity of subject content compared to the 2006 version, suggests that the ownership of the science curriculum has shifted once again towards the professional scientists.

The 2015 curriculum is much more detailed; the curriculum for the separate sciences for 1416s is 52 pages in length including appendices. In a new approach for the English National Curriculum, each segment of the curriculum has the uses of mathematics laid out alongside it. For example, the subunit on the 'Rate and Extent of Chemical Change' includes the following mathematics:

- arithmetic computation, ratio when measuring rates of reaction

- drawing and interpreting appropriate graphs from data to determine rate of reaction

- determining gradients of graphs as a measure of rate of change to determine rate

- proportionality when comparing factors affecting rate of reaction. (DfE, 2015, p. 26)

The physics curriculum includes 14 different 3-part equations which must be memorised and used, together with several other examples of equations (DfE, 2015).

\section{Science education in England}

The National Curriculum for science was first introduced in 1989.-Seience and is compulsory for all students from the ages of 5-16. Previously there were external assessments in science at 11 and 14 but these were abolished in 2009 and 2008 respectively. At age 16 students sit GCSE examinations which are external, high stakes assessments. Education beyond 16 is optional with about $50 \%$ of the cohort choosing to follow Advanced or A-levels, with most studying three subjects for two years leading to further high stakes assessments. A-levels are only an option for students who attain a high enough grade in the GCSE. No subject is compulsory, leading to participation particularly in mathematics being substantially lower than the OECD average (Hodgen, Pepper, \& Ruddock, 2010). The picture is further complicated as there are three competing awarding organisations which write examinations from the government-produced curriculum.

\section{Mathematics in the science curriculum}

The National Cumieum for seing several revisions, there was a very limited quantity of mathematics within the science curriculum. Orton and Roper (2000), mathematics educators, even argued that science education was apparently trying to manage without mathematics, or at least to include as little 
as possible. Indeed, one examination board could claim that 'Candidates will not be prevented from demonstrating achievement in science by the use of [...] mathematics which is excessively demanding' (quoted in Orton \& Roper, 2000, p. 130).

In their review of the 11-14 curriculum Orton and Roper (2000), both mathematics educators, note that the data handling requirements in science assessments were higher than those in the mathematics assessments but that aside from this the mathematical demands were not high and fell well within the equivalent levels for mathematics. Fairbrother (2008), a science educator, was more critical of the lower mathematical demands in the science compared to the mathematics 11-14 curriculum.

This mismatch represents an oversimplification of science, a failure properly to show what science at this level is about, a lack of opportunity for students to show what they can do and a failure to prepare students for the GCSE examination. It also fails to take advantage of using the same concepts and operations in science and mathematics to reinforce pupils' knowledge and understanding in both subjects. (Fairbrother, 2008, p. 112)

In the late 2000s, SCORE commissioned a series of studies about the content of science examinations. The reports indicated that for GCSE the full range of mathematics skills and techniques given within the specifications were not being assessed and the demand of the mathematical questions was limited (SCORE, 2009). The same problems were identified in A-level papers where the mathematics in examinations clustered around a few types of mathematics across all papers and was not a broad spread of all the potential mathematics according to the examination criteria (SCORE, 2012). This was even true in physics assessments, where the most mathematics was found.

There was far from universal agreement as to how problematic the small percentage of mathematical questions within science assessments actually was. Members of the scientific community were shown the data and the authors reported they felt that chemistry examinations, in particular, should be only concerned with chemistry rather than mathematics. In other words, it is not enough that a science examination should contain mathematics; questions should be in the context of science and require scientific knowledge and understanding.

Since 2015, the percentage of the marks which must be mathematical for each of the science subjects is specified for both GCSE and A-level. It ranges from $10 \%$ for biology to $40 \%$ for some physics assessments.

Mathematical content in some science qualifications was higher prior to the introduction of the national-National eurriculum-Curriculum in 1988 and some of the calls for an increase in mathematics in science examinations seem to be harking back to this previous era. For example, the Science and Learning Expert Group report to the government, which specifically recommended an increase in mathematics in science qualifications, found that:

There was near universal agreement that the level of mathematics in science at GCSE and A-level has been significantly reduced. (Science and Learning Expert Group, 2010, p. 110) 
However, science teaching in the 1980s was not without its problems. There were two separate qualifications for 16 year olds; CSEs for the majority and O-levels for about 25 percent of the school population. Even some of the mathematical requirements of O-levels were deemed just too hard for this group (Shayer \& Adey, 1981). Shayer and Adey argued using a Piagetian analysis that the cognitive demands of secondary science were too high and that the mathematics which was focused on was often not the most appropriate. Even in the National Curriculum era, Dodd and Bone (1995) found that much of the mathematical content of early versions of the science curriculum for 11-13 year olds was simply too hard for students. The converse view is that removing mathematics from the curriculum misrepresents science (Orton \& Roper, 2000; Fairbrother, 2008; Osborne, 2011); the level of mathematics which 'should' be present in the science curriculum is seemingly always going to be a matter of contention.

\section{$\underline{\text { Research Questions }}$}

The term policy is commonly used but difficult to define (Hill, 2013). Ball suggests policy is not a finished product but a process, which is ongoing, interactional and frequently 'messy, eontradictory, confused and unclear' $(2013$, p. 8). In this paper, 1 This paper asks what the influences, ideologies and values are behind a particular policy, namely significantly increasing the amount of mathematics in the science curriculum, and Iuses this particular case to explore the struggles and contested nature of science in the curriculum.

The term policy is commonly used but difficult to define (Hill, 2013). Ball suggests policy is not a finished product but a process, which is ongoing, interactional and frequently 'messy, contradictory, confused and unclear' $(2013$, p. 8).

I use Hill's concept of ideology:

A more-or-less coherent set of beliefs and attitudes that is regarded as self-evidentially true, as 'common sense'. (Hill, 2001)

And draw on Halstead's definition of values:

Principles, fundamental convictions, ideals, standards or life stances which act as general guides to behaviour or as points of reference in decision making $(1996$, p. 5).

In this study, the ideology and values underpinning the science curriculum are explored via interviews with relevant stakeholders and through the analysis of government (and other influential) reports and policy documents.

\section{Theoretical framework}

\section{Academic disciplines and school subjects}

Several authors have written about the relationship between academic disciplines and school subjects (for example, Ball, 1990, Bernstein, 2000, Watson, 2008 and Chevallard and Bosch, 2013). Their ideas will be useful in analysing the values and ideology underpinning the changes to the amount of mathematics in science. A school subject is not the same as the academic discipline to which it is related. Each of the sciences and mathematics are academic disciplines which cannot be taught in schools without being suitably adapted. 
Bernstein (2000) suggests discourses are selectively appropriated, relocated, refocused and related to other discourses to constitute the new pedagogic discourse, or school subject, a process he calls recontextualisation. Note that it is plural - other discourses. Material may be drawn from more than one academic discipline to constitute a school subject. This pedagogic discourse is not the same as the academic disciplines:

Pedagogic discourse is not physics, chemistry or psychology. Whatever it is, it cannot be identified with the discourses it transmits. (Bernstein, 2000, p. 32)

The original discourses, in this case the academic disciplines of physics, mathematics, chemistry, biology, are taken from what Bernstein calls their original site of effectiveness to a pedagogic site. As this happens a gap is created between the original and the pedagogic, and ideology ean-operates in that gap:

As the discourse moves from its original site to its new positioning as pedagogic discourse, a transformation takes place [...] because every time a discourse moves from one position to another there is a space in which ideology can play. No discourse ever moves without ideology at play. (Bernstein, 2000, p. 32)

This transformation is not usually done by those who are active in the academic field. The authors of school chemistry textbooks, or chemistry curricula, for example, are rarely practising chemists. Those doing the recontextualising will select the content of the school chemistry curriculum from the totality of the academic discipline of chemistry, and from other disciplines including geology and materials science. In addition they will select and make choices about how chemistry is related to other subjects and the sequencing and pacing of the curriculum (Bernstein, 2000).

$\underline{\text { Similar to Bernstein's idea of recontextualising knowledge, and more popular on mainland }}$ Europe, is the theory of didactic transposition. Didactic transposition is the modification of knowledge for instructional purposes. Bosch and Gascón (2006) argue this process is creative, not just transferring, adapting or simplifying, as the different elements of the knowledge are deconstructed and rebuilt to make them 'teachable.' This creative work is done by a number of agents including politicians, scholars and members of the teaching system, particularly teachers. Their main aim, according to Chevallard and Bosch is:

to negotiate and cope with the demands made on society by the teaching system, while preserving the illusion of 'authenticity' of the knowledge taught at school, thus possibly denying the existence of the process of didactic transposition itself. [...] the body of knowledge taught at school under the label of [science] has to appear as genuine. It is thus important to understand the choices made in the designation of the knowledge to be taught and the construction of the taught knowledge. (2013, n.p.)

Various interest groups, each with their own particular bias and interests, seek to influence the content and construction of the curriculum. Bernstein argued that:

Curricula reform emerges out of a struggle between different groups to make their bias (and focus) state policy and practice. (2000, p. 65) 
Ball (1990), in his study of the Education Reform Act and the writing of the first National Curriculum in England, also notes that educational curricula are always a compromise between different interest groups. These groups are active in the policy arena and each try to impose their own ideology on the construction of school curricula. The 'outcome of these compromises are different at different historical moments' (p. 214, emphasis in original), as can be seen in the very different versions of the national-National eurriculum-Curriculum for science as discussed above. Thus understanding the ideology and the compromises is important in understanding the resulting curriculum.

Like Chevallard and Bosch (2013), Watson recognises that there is a difference between the original and the pedagogic discourse, acknowledging that however much one might want students to undertake activities in school which are 'authentic', school mathematics is not the same as the broader discipline of mathematics, which she takes to mean the advance of mathematical knowledge.

School mathematics is not, and perhaps never can be, a subset of the recognised discipline of mathematics, because it has different warrants, authorities, forms of reasoning, core activities, purposes and unifying concepts, and necessarily truncates mathematical activity in ways that are different from those of the discipline. (2008, p. 3)

The same could be argued for the school sciences.

Singh (2002) uses the language and ideas to-of Bernstein to argue that those who are undertaking the work of pedagogising knowledge have the power to decide what knowledge is chosen, in other words what the school subject looks like, what it contains and who it is aimed at. Fensham argues that inevitably science education policy, and resultant curricula, value or prioritise some groups in society over others (2009).

\section{Contesting the curriculum}

Ball (1990) suggests that the National Curriculum arose out of concerns, expressed by both right and left wing politicians through the 1960s-1980s, that there was a problem, or even a crisis with, particularly state, education in England. One substantive theme he identified in the discourse is that of academic standards, particularly numeracy standards, being in decline. This has remained a constant refrain of education ministers to this day and, as it was then, is linked to concerns about economic competitiveness, with the prevailing political ideology being that education must serve the economy (Hill, 2013).

Apple, in a paper discussing the purpose of national curricula, identifies a focus on industry and the economy in education in the US, linked to arguments about standards. He argues that the very existence of a national curriculum was crucial to a government wanting to be seen to be 'doing something about raising standards' (1993, p. 7).

Apple further argues that a 'national curriculum is a mechanism for the political control of knowledge' (1993, p. 9). In other words, it allows the government to decide what is taught in schools rather than leaving that decision to teachers who might otherwise make curricular choices of which the government would not approve.

The curriculum and disputes about what would constitute a valid curriculum were central to concerns about standards and political control of knowledge in the writing of the first nationat 
National eurriculum-Curriculum in England (Ball, 1990). Material that was 'relevant' to the student was believed to be taking the place of the harder subjects. The assumption was that new studies and subject matter were necessarily political and biased whereas the traditional subjects were 'unquestionably neutral and objective' (Ball, 1990, p. 48)

The inclusion and exclusion of particular subjects was an issue then (Ball, 1990) and continues to be so over 25 years later. The nature and conception of those subjects is also disputed. What counts as mathematics or science was the basis of competition between interest groups (Ball, 1990). This is Bernstein's 'gap in which ideology can play' (2000, p.32). Indeed, Apple argues that just having a national curriculum is the spur to intense debate about whose knowledge - or version of science - is declared official (1993).

Fensham (2013) argues that the role of science within the national curriculum, in England and internationally, has been an ongoing sub-contest with its own distinctive agenda. This is due to the strategic role science plays in a number of key professions, and because of its significance to the public, economic and environmental well-being of modern societies. He previously (2009) identified seven demands on science education: subject maintenance, economic, political, environmental, cultural, social and individual. He suggests that the interplay of these demands can lead to very different science education policies and curricula, depending on whether the predominant demand is for the next generation of scientists or for scientific understanding for the public at large.

In summary, then, in order to ask what the influences, ideologies and values are behind the increase of mathematics in science, it will therefore be informative to analyse the data collected in this study will be analysed in the light of the arguments advanced by these authorsdiscussed above. In particular, Chevallard and Bosch (2013) argue that it is important to understand the choices made in the designation of taught knowledge, or writing of the curriculum. In particular, Ball (1990) and Apple (1993) suggest that governments are concerned about standards and those concerns are likely to be made manifest in policy making. Following Bernstein (2000) and Ball (1990), I will ask what thethe ideologies are which are driving curriculum choices will be explored. Chevallard and Bosch (2013) and Watson (2008) argues that school mathematics cannot be 'authentic', in other words the same as the discipline of mathematics; is that recognition clear in science curriculum policy making? It will also be important to explore, as discussed by Singh (2002) and Fensham (2009), who the curriculum is aimed atSingh (2002) and Fensham (2009) suggest that it is important to explore who the curriculum is aimed at.

\section{Research methods}

A two-phase qualitative study was undertaken to try to understand the drivers and arguments for changing the amount of mathematics in science, $\bar{y}_{2}$ through published government documentation and through semi-structured interviews with some of those closely involved in the development of both the mathematics and science curricula.

\footnotetext{
The first phase consisted of an analysis of UK government andher influentialdoements relating to mathematies and seien 2000 . The dowments

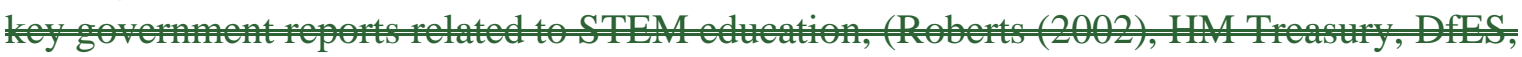
DTI (2004), DfES (2006), HM Tre DTI, DfES, DणH (2006), Sains (2007); NFER (2011)) Seience and mathematies
} 
Expert Group, 2010), Making mathematies (Smith, A, 2004), Ofqual A tevel rew (Smith M., 2013), the National Curriculum programmes of suly foth mathematies and the pulish this (DfE 2013a, 2013b, 2013e, 2014, 2015; DfE and QCDA 2004; (QCA, 2006) and the subje CESEs (Ofqual, 2016). In addition I

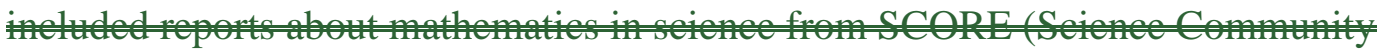

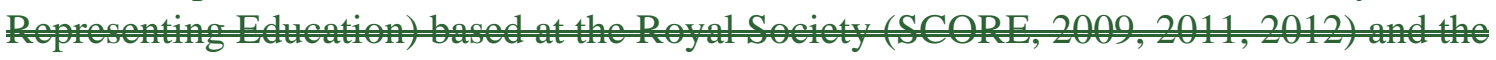

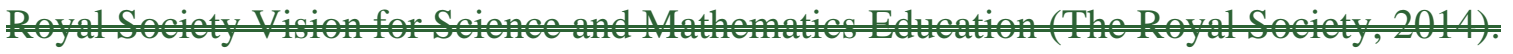
Finally, I include three reports from the Higher Edueation Academy fousing on mathematical transitions from shol to higheducation: the biosienes (Konig, 2011); 7. 2011); ehemistry (Hodgen, McAlinden, \& Tomei, 2014). Ideas and ation points relating to mathematical content of science were from the doements and displayed in hapt

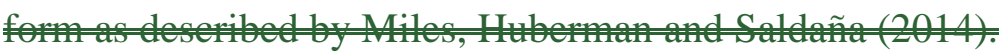

In phase two The first phase consisted of ; semi-structured interviews were conducted during 2013-2014 with 21 long-standing and acknowledged key contributors to the science and/or mathematics education discourse in England, including an engineering educator and a retired civil servant. The second involved an analysis of UK government and other influential documents relating to mathematics and science education since 2000.

\section{Interviewees}

Interviewees for this study were selected on the basis that they had had some influence on government science or mathematics education policy in the last 30 years. All have influenced the development of the national curriculum and/or worked as government advisors and/or worked for charitable trusts and learned societies and/or sat on the government High Level STEM strategy group.

Some initial interviewees were selected and each participant asked for recommendations or introductions to other potential interviewees. All interviews were conducted by the author, who has worked in science education in England for several years. The interviewer 'exploited pre-existing links with those in power' (Walford, 2012, p. 112) to gain access to initial participants and then used a reputational snowball by asking interviewees to 'identify others in the field who are particularly influential, important or worth contacting' (Cohen, Manion, \& Morrison, 2011, p. 159).

Care was taken to ensure that there was a balance of disciplinary backgrounds among the science educators, with four physicists, four chemists and three biologists included. Interviewing was continued until it seemed that subsequent interviews, while offering interesting individual perspectives, were not offering anything that was substantively new; that is, data saturation was reached (Rubin \& Rubin, 1995). Identifying the key stakeholders is the main limitation of the methods used. The key stakeholders may not all have been identified, interviewing may have stopped too soon and those who declined to be interviewed may have had a unique perspective which is missing from the data. The choice to have a balance of science disciplines may have contributed to skewing the data. A further limitation was a lower acceptance rate for mathematics educators than science educators. This is partly due to the author being less well known in the field of mathematics. Mathematics educators also declined to take part due to lack of interest in the relationship with science. Thus the data collected represent mathematicians, in particular, who have more interest in STEM and in 
collaborating with science. The data set is thus probably skewed towards the views of those with positive conceptions of STEM and mathematics-science collaboration. While this is a limitation, Jenkins (2012) argues that there are considerable aspects of policy formulation that are rarely open to contemporary scrutiny. Thus even the limited access offered in this study is unusual and consequently of interest. Interrogating all interview findings against the analysis of the publically available documents helps to ensure that the findings can be trusted.

Each of the policy maker participants was given a two or three letter pseudonym to maintain anonymity. The first letter represents their discipline (mathematics, science, engineering, civil service), the second a letter to identify them. Ethical approval for the research was granted by <institution>King's College London and BERA guidelines for ethical research were followed (BERA, 2011).

\section{The interviews}

The original study design called for entirely face-to-face interviews, but the contingencies of the data collection meant that some telephone interviews were used. These were due to interviewee preference and covered one ill and two retired interviewees. Sturges and Hanrahan (2004, p. 108) in comparing telephone and face-to-face data within the same study, concluded that there was no significant difference between the two interview modes and that telephone interviewing can be used successfully in qualitative research. Overall, though, faceto-face interviewing was used wherever possible, as not seeing the participant deprives the interviewer of access to non-verbal communication during the interview. The first phase consisted of an analysis of UK government and other influential documents relating to mathematics and science education since 2000. The documents used were the six key government reports related to STEM education. (Roberts (2002), HM Treasury, DfES, DTH (2004), DfES (2006), HM Treasury, DTI, DfES, DoH (2006), Sainsbury (2007); NFER (2011)) Science and mathematics education for the $21^{\text {st }}$ Century (Science and Learning Expert Group, 2010), Making mathematic count (Smith, A., 2004), Ofaunl A level review (Smith M., 2013), the National Curriculum programmes of study for both mathematics and the sciences published this century (DfE 2013a, 2013b, 2013c, 2014, 2015; DfE and QCDA 2004; QCA, 2006) and the subject criteria for science GCSES (Ofqual, 2016). In additionI included reports about mathematics in science from SCORE (Science Community Representing Education) based at the Royal Society (SCORE, 2009, 2011, 2012) and the Royal Society Vision for Science and Mathematics Education (The Royal Society, 2014). Finally, Iincluded three reports from the Higher Education Academy focusing on mathematical transitions from school to higher education: the biosciences (Koenig, 2011); physies and engineering (Morgan, 2011); and across a range of other subjects including chemistry (Hodgen, McAlinden, \& Tomei, 2014). Ideas and action points relating to mathematical content of science were condensed from the documents and displayed in chart form as described by Miles, Huberman and Saldaña (2014).

\section{Interview Analysis}

Interviews were transcribed and analysed using thematic analysis (Braun \& Clarke, 2013). The data were coded using a complete coding process, using NVIVO 10 to manage the data. Some deductive (based on theoretical background) codes were used, but the majority were inductive, based on the data and staying close to what participants said, in a grounded 
approach as described by Charmaz (2006). From these codes themes were identified which captured patterned response and meaning within the data set. Findings from interviews were checked against each other and discussed with colleagues to ensure reliability and validity.

\section{Document analysis}

As discussed above, the interview data set is probably skewed towards the views of those with positive conceptions of STEM and mathematics-science collaboration. Interrogating all interview findings against the analysis of the publically available documents helps to ensure that the findings can be trusted.

The documents used were the six key government reports related to STEM education, (Roberts (2002), HM Treasury, DfES, DTI (2004), DfES (2006), HM Treasury, DTI, DfES, DoH (2006), Sainsbury (2007); NFER (2011)) Science and mathematics education for the $21^{\text {st }}$ Century (Science and Learning Expert Group, 2010), Making mathematics count (Smith, A., 2004), Ofqual A-level review (Smith M., 2013), the National Curriculum programmes of study for both mathematics and the sciences published this century (DfE 2013a, 2013b, 2013c, 2014, 2015; DfE and QCDA 2004; QCA, 2006) and the subject criteria for science GCSEs (Ofqual, 2016). In addition reports about mathematics in science from SCORE (SCORE, 2009, 2011, 2012) and the Royal Society Vision for Science and Mathematics Education (The Royal Society, 2014)were included. And finally three reports from the Higher Education Academy focusing on mathematical transitions from school to higher education: the biosciences (Koenig, 2011); physics and engineering (Morgan, 2011); and across a range of other subjects including chemistry (Hodgen, McAlinden, \& Tomei, 2014). Ideas and action points relating to mathematical content of science were condensed from the documents and displayed in chart form as described by Miles, Huberman and Saldaña (2014).

Finally, the interview data were compared with data from the document analysis and comparisons drawn. Findings came predominantly from the interview data which were interrogated against the document analysis, with particular attention paid to differences between the document analysis and the interview data. . Six themes Seven drivers were identified in how the participants articulated the reasons for changing the amount of mathematics present within science.

\section{Findings}

From the interview data, seven drivers were identified which impact the amount of mathematics within science. Four of these drivers lead to pressure for more mathematics in the science curriculum (concern about standards, transition, authentic science, and improving students' mathematical confidence and achievement) and three lead to pressure for less mathematics in science (qualitative science, accessible science and student numbers). Although the amount of science within the mathematics curricula is virtually non-existent (DfE 2013a, 2013b), there are minimal calls for a change in how much science is incorporated within mathematics from either the interviewees or from the documentation.

It is worth noting that although extensive concerns about the science curriculum more broadly are expressed, specific mention of mathematics in science is not in evidence in the government STEM or other earlier documents analysed. The first mention of mathematics in science is in the first SCORE report on examinations (SCORE, 2009), with the issue also being raised the following year by the Science and Learning Expert Group (2010) and in 
subsequent reports. Both these reports follow the introduction of a new GCSE curriculum in 2006.

\section{(1) Concern about standards}

As anticipated by Ball (1990) and Apple (1993), concerns were raised about standards. Indeed, over half the interviewees noted broad concerns about falling standards across the curriculum, particularly in science. That standards are still an over-riding concern was highlighted by CSA:

The main preoccupation of the Department [for Education] was around the basic standards of education, particularly in English and maths. [...] And that remains, I think, very much the department's focus. [CSA]

Concern about standards was also noted in a number of the reports. For example, the Science and Learning Expert Group discussed the need for a 'rigorous curriculum' (2010, p.45) and explicitly linked this to the need for an increase in mathematics in science. Several respondents suggested the addition of more mathematics into the latest iteration of the science curriculum was a government response to the problem of standards. For example:

GCSE [science] standards have fallen, how can we make them rise, well, let's put maths in, because that's got to make them harder. [MG]

In other words, raising standards here is being conflated with making the curriculum harder or more rigorous. However, some of the interviewees expressed conflicting feelings about the purpose of the additional mathematics. Many were broadly supportive of including more mathematics on the basis that much of science is quantitative, but some were uncertain that the way the curriculum was being developed was necessarily helpful. SJ summed up this position:

If you think this [addition of mathematics] is going to beef up science and make it more respectable, I don't think that's a good reason. If what it's doing is helping teachers and therefore helping children to understand the value of when you need to be quantitative, then that's fine. [SJ]

'Beefing up' here is being used to suggest that science and science assessments will be more challenging, with SJ arguing that some people might think this would make them more respectable, or raise standards.

Thus the notion that increasing the amount of mathematics will improve the rigour or standards of school science is a key driver in the development of recent science curriculum policy. The issue of raising standards and making the curriculum harder was not limited to science alone in the most recent curriculum and was a concern of the government across multiple subjects (Young, 2011). Whether the inclusion of more mathematics in science will genuinely raise standards or increase rigour, whatever either means in reality, is not yet clear.

\section{(2) Transition}

In recent years, higher education institutions and the learned societies have raised concerns about students' difficulties with mathematical transitions from one level of science education to another as reported by the Science and Learning Expert Group (2010), Keonig (2011) and Morgan (2011). The issue of transition was raised in the first government STEM report (Roberts, 2002), and several of the other documents analysed. Likewise, over half of the 
participants raised issues regarding transition; many of these concerns have focused on students' use of mathematics in other subjects including the sciences and engineering. For example:

The reason why folks seem to care about the maths content of science A-levels [...] is the transition to higher education. [EA]

The Science and Learning Expert Group Report to the government was focused on increasing numbers in post-compulsory science and mathematics education and on increasing opportunities 'for stretch and challenge for the most able learners' (SLEG, 2010, p. 76). It specifically recommended that 'the mathematics content should be boosted substantially within 14-19 science education' and particularly the mathematics 'needed for progress in STEM beyond school/college' (ibid., p. 12). Koenig agreed, calling for 'a more significant mathematical component in A level biology and chemistry' (Koenig, 2011, p. 1) to support students in bioscience degrees. Minimum percentages of marks for mathematics in science qualifications (Ofqual, 2016), which had never been included previously, were introduced for both science GCSE and A-level qualifications from 2018. This minimum percentage was recommended for A-levels by Smith in his report for Ofqual (2013), but extended to GCSEs, which were beyond Smith's remit. SD suggested that the increase of mathematical content in science GCSEs had come directly from universities' concerns about undergraduates' use of mathematics, including in the biosciences:

What universities and biologists say about the subject [is that] students need to understand that it is a quantitative subject, it is not a purely descriptive subject [...]. That has become putting an awful lot of [mathematical] content into GCSE sciences. [SD]

Concerns about transition are particularly focused on students who might choose to study science subjects beyond school level, which is clearly only a minority of the total cohort, particularly in compulsory (pre-16) education.

\section{(3) Authentic science}

One idea which recurred in the interviews was that as science, or STEM, subjects are largely mathematical in nature, particularly in higher education and professional contexts, then so should they be mathematical in school in order to give an accurate or authentic idea to students about the nature of the subject, as the following quotes exemplify:

The STEM subjects are inherently mathematical. And as they are supposed to be a preparation for further study then where there is quite a lot of mathematics, particularly in physics, then if you don't introduce the fact that there is some mathematics at this stage then you're probably not giving people the right message about what they might expect when they come for further study. [SA]

I'd certainly like to see more maths in the physics, to give it a more authentic feel [...] The students are not well prepared for further study, they don't get an authentic feel of the subject. [SI]

Concerns about authenticity which were raised focused, as in the two quotes above, largely on future, rather than current, study. In other words, it is important that students who will continue to study the subjects have an authentic impression of science. The authentic science 
argument was not explicitly present in many of the documents analysed, but did appear in two reports, both focused on transition to university education. Koenig (2011) argues that lack of mathematical content at A-level means that students do not expect to encounter it in bioscience degrees. Morgan (2011) suggests that some students choose to study mathematics rather than physics as they do not appreciate the mathematical nature of physics.

Thus adding mathematics to science qualifications to make them 'authentic' is primarily for the benefit of the minority of students who will progress to the next educational stage.

\section{(4) Improving students' mathematical confidence and achievement}

One of the reasons given for an increase in the mathematical content of the science curriculum is to improve students' mathematics skills, as the following quote exemplifies:

Mathematics is like a language or like music, you have to practice it. And if you're only practicing it in maths lessons, it's like learning a language and only practising it when you're being taught French [...] And so by stripping maths out of science and geography and anywhere else it was to be found, you actually hit maths education as well as hitting science education. [SH]

MA went further, suggesting that reducing the amount of mathematics in science education had:

been absolutely fatal, I think, to both science and maths. Actually it's been a really bad move. [MA]

The idea that including mathematical skills within science can contribute to students' mathematical development can also be found in the documentation, although it is not very prevalent. One example:

Mathematics has been demonstrated to be one of the best ways to improve logical skills [...] The study of science backed with solid mathematical content also helps develop such skills. (The Royal Society, 2014, p. 67)

Smith (2013) also identified the need to strengthen the mathematical skills of science A-level students. He directly linked this need to the recommendation of a minimum percentage of mathematics in science A-levels.

Unlike the previous two drivers, this driver is aimed at all students.

The next three drivers are distinct from the previous ones in that they are a call for less mathematics in science, or more qualitative science.

\section{(5) Qualitative science}

Some respondents questioned the notion that students needed to have met mathematical ideas in mathematics lessons before using the concepts in science, arguing that a qualitative approach may be preferable at times in science. A call for a qualitative approach challenges the view held by some participants that adding in mathematics necessarily makes the science more 'authentic' or more 'rigorous' (as discussed above) and therefore that the removal of mathematics from the science curriculum must be avoided at all costs. SF argued that there is a case for ensuring that students have a qualitative understanding before introducing numbers, which could lead to an improved understanding of the science and consequently what the numbers actually represent. 
There is an argument that a qualitative feeling for an explanation should precede the formulaic approach. [That] you should teach more graphical and visual forms of data analysis, exploratory data analysis and the techniques of exploratory data analysis, before you get into the formality of the symbolic formulae. [SF]

SJ agreed that it did not have to be the case that mathematics had to be the foundation subject which must be learnt before applying it in science, similarly challenging the view that science in school necessarily has to build on mathematical foundations:

This idea that maths is the foundation, you learn your numeracy and then your graphicacy and then you apply it in science. [...Instead] you can go from jumping into something that's interesting and then tease out the fundamentals. That seemed to me to be lacking in a lot of the discussions between scientists and mathematicians, it was always the assumption that you needed to get the maths foundations sound first, rather than use the context of science and technology to say 'we really need maths to sort this out'. [SJ]

SJ further gave the specific example of graph drawing to argue that you could understand what a graph is showing before you could write an algebraic equation to describe it:

Can we reverse this and say, right, well, we won't have the skill to understand what the equation of a line graph is, but at least you can get some sense, which is very important in science, of the relationship between two quantities; this gets bigger as that gets bigger. That is an easier idea than to write it down algebraically. [SJ]

Such calls for a more qualitative approach in science, at least some of the time, challenges the idea that if students do not cover everything in a 'rigorous' mathematical way then it somehow undermines or misrepresents science, or that what they are doing is not properly science. A qualitative approach could be supportive of the mathematics curriculum if, as SJ suggests, it is used to point to the need for mathematics, although it is not entirely clear how this could realistically be achieved in school. This driver is noticeably lacking from the documentary analysis.

\section{(6) Accessible science}

There was acknowledgement from some science educator participants that the science curriculum and assessments had changed over time as a result of science now being studied by all students; all of those who mentioned this change were supportive of the idea of 'science for all'. For example:

If you read the Newsom report [Newsom, 1963] you will see that nobody had a clue how to teach science to anybody other than in the grammar school cohort. Now our ambition is to teach worthwhile science and mathematics to everybody and that in a pretty undifferentiated way. [...] We've gone for encouraging more people to progress with education than in the days of the grammar schools, and that affects the demands you can make on people. [SF]

Part of this change has included less mathematics within science than might have been expected of the grammar school cohort, which was usually around 25 per cent of the school population: 
There's been a de-mathematising of science. And it's been part of the move towards universal science education. So if you wound the clock back to the 1970s, science was essentially something that an elite did [...]. When GCSE came in and when A-level moved from being something that 10 per cent of the population does to something that nearer to 50 per cent does, people looked for ways to make them more accessible to that wider ability group. [SH]

That the reduction in mathematical content was deliberately done to make science more accessible can be seen in the claim from the NEAB examination board in the 1990s that: 'Candidates will not be prevented from demonstrating achievement in science by the use of [...] mathematics which is excessively demanding' (quoted in Orton \& Roper, 2000, p. 130).

For SF, it is important that students experience success in doing science as it will lead to them finding it rewarding, particularly when it is compulsory for all.

My view [is that it is] better to do less and experience success than to do more and experience failure. [...] Now, Michael Gove [Secretary of State for Education 20102014] will say no, if you lower the bar like that you cheat people, but the alternative view is that above all up to the age of 16 you must keep people engaged in education and feeling it's rewarding. [SF]

In other words, as science is offered to all then it must be appropriate for all, even if some students might be capable of more.

This theme is not widely present in the document analysis but the Science and Learning Expert Group report acknowledged that increasing the mathematical content of science could be challenging for some students:

We acknowledge that some students can find mathematics daunting, but if the material is taught and assessed well, demanding mathematics content can be made accessible to a wider audience and rather than providing a blockage, should enhance science learning and motivate learners through a deeper grasp of the subject. (2010, p. 45)

That demanding mathematics content 'should' enhance science learning and motivation is perhaps a recognition that there is very limited research to support such a supposition.

\section{(7) Numbers of students in post-compulsory education}

Concern about numbers of students taking sciences in post compulsory education, 16-18 as well as at undergraduate level, are found throughout the STEM documentation. There was some question among interviewees about whether this concern led to a reduction in mathematics within science. For example:

My sense is that people [...] worried that if there was too much maths, they'd have recruitment issues and recruitment was seen as a problem. [MH]

It was also acknowledged by some that the most recent increase in the amount of mathematics in science may cause the numbers of students opting for sciences to decrease:

If you put more maths in [science qualifications], it will seem harder and that may put some young people off. I think it's a risk we've got to take. [SH] 
This concern is also expressed in the documentary analysis. For example, the Science and Learning Expert Group (2010) argued that increasing the level of mathematics in science may reduce take up, but nonetheless the amount should be increased.

\section{Discussion}

It is thus demenstrated that $\mathrm{t}$ There are therefore a number of arguments for either increasing or decreasing the amount of mathematics within science. No one suggested at what point, if any, the amount of mathematics within science was ideal.

Ball (1990) and Apple (1993) suggest that concern about standards is prevalent in government discussion of national curricula and, indeed, this concern was very evident in the findings. The need to raise standards is discussed as self-evident or common sense and is thus ideologically driven, according to Hill's (2001) definition. However, adding more mathematics to science will not necessarily make science more 'rigorous' or raise standards. The ICCAMS study into secondary students' understanding of mathematics argued that teaching students aspects of mathematics because they have to be taught to that particular age group, regardless of whether they have a firm grasp of pre-requisite material, may contribute to the lowering of standards rather than raising them (Hodgen, Kuchemann, Brown, \& Coe, 2009). Thus iff students do not understand the mathematics which is being used in science it will not necessarily, therefore, raise standards as intended.

Bernstein (2000) identified that when an academic discipline is turned into a school subject ideology always ean-comes into play. Ideologies are beliefs which are held as selfevidentially true or common sense (Hill, 2001). A number of the participants suggested that school science should aim to be 'authentic' to give an accurate impression of science, with more mathematics a key part of this desired authenticity. Holding that school science must be 'authentic' and consequently mathematical is an ideological position which can inform and drive the transformation of the discipline into pedagogic discourse and drive the content, pacing and how science is related to other subjects, including mathematics.

While having science in school being 'authentic' initially sounds benign and a worthwhile aim, there are two problems with having this as an ideology driving curriculum policy. The first is that it ignores the fact that school science is not, and never can be, the same as 'authentic science', even if there were an agreed definition for the nature of science. Watson (2008) recognised the distinction between mathematics as a discipline and school mathematics. The same is true for school science: it thus-is not, and cannot be, a subset of the discourse of science. Furthermore, Jenkins (2007) argues that school science is itself a questionable construct, and that given the differences between the disciplines - including the ways in which they use mathematics - it might be better to acknowledge these through using sciences, plural, instead.

The second problem with having 'authentic' science as a curricular aim is that it tends to lead to the needs of those who will go on to further study being prioritised. It is they who need to be given the authentic experience, to be shown what the subject is properly like, so that they know what they are choosing when they continue studying. None of the interviewees suggested that those who would stop studying science needed an authentic view of the subject, but several related the need for authentic science to concerns about transition and student numbers. 
Chevallard and Bosch (2013) call the notion of authenticity an 'illusion' which may seek to deny the existence of didactic transposition, or recontextualisation. They explicitly link this desire for knowledge to appear authentic to the importance of understanding choices made in curriculum design.

Singh (2002) and Fensham (2009) argue that it is important to identify who the curriculum is aimed at. The aim of improving students' overall mathematical confidence and achievement could be seen as being aimed atfor all students. These arguments have echoes of the 1980s 'Education through science' agenda as advanced by the ASE (1981). There is, however, very limited evidence that using mathematics in science improves students' attainment in mathematics (Wong, 2018). If improving the mathematical competence of all students is indeed a driver for increasing the proportion of mathematics in school science then there is an urgent need for further research to understand whether encountering more mathematics in science does indeed help with mathematical confidence and competence.

However, several of the drivers for changing the amount of mathematics in science are focused on the needs of those likely to continue to study science in post-compulsory education; a minority of the cohort. These drivers include concerns about transition, concerns about student numbers and the drive for authentic science. The limited focus on accessible or qualitative science and the much greater focus on transition and student numbers (in both the interview and documentary data) suggest that the predominant demand of this curriculum is for the next generation of scientists. It could be, though, that a 'science for all' approach to curriculum design could help to increase the uptake of the sciences in post-compulsory education. The need for science for all and the need for more scientists are not necessarily mutually exclusive.

This study can also be viewed within the broader national and international context. Nationally, the science curriculum is one part of a larger curriculum change instituted by the former Secretary of State for Education, Michael Gove. Young (2011) argues that this curriculum is based on subjects, with both the range of subjects to be included and the boundaries around those subjects largely a given. Young further suggests that this curriculum offers a vision of schooling as an intellectual challenge for students and teachers, offering students the opportunity to engage with the knowledge that has been produced by specialist scholars in the disciplines from which the school subjects are drawn.

Internationally, Hollins and Reiss (2016) found that western jurisdictions are tending to develop tighter, more knowledge-focused, specifications for science content and teaching. The much greater specificity of subject content in the latest English science curriculum fits within this broader trend. With specific reference to mathematics in science, however, England does not seem to follow international trends. Clesham (2013) found that there was a low incidence of calculation questions in school science examination questions internationally. The regulator, Ofqual, in a report into A-level chemistry, even asked if there was too much mathematics in chemistry A-levels as the mathematics requirement was higher than in other similar examinations internationally, although it noted that most other jurisdictions required the separate study of mathematics (Ofqual, 2012). Both reports were published prior to recent increases in mathematical content.

The desire for authenticity in school subjects is not limited to either science education nor to education in England. Chevellard and Bosch, whose work is mainly conducted in French- 
speaking contexts, highlight the 'illusion of authenticity' (2013, n.p.) which can be used to deny the existence of the work of didactic transposition.

\section{Conclusions}

Thus the science curriculum being hotly contested with various groups presenting demands (Fensham, 2009) can be seen in the range of drivers for the amount of mathematics in the curriculum as in other aspects of science. Indeed, the Science and Learning expert group acknowledged:

potential tension between the 'stretch and challenge' and 'widening participation' agendas, as well as between competing opinions within the science and mathematics communities. (2010, p. 106).

Similarly, Osborne and Dillon (2008) argue that across Europe, science is unusual as a school subject in the way that the needs of students who may go on to further study are set against the needs of the majority.

The increase in mathematics in science is a choice by curriculum designers, strongly influenced by broader government policy initiatives. These choices are ideologically driven: the need for an increase in standards, 30 years on from the introduction of the first national curriculum with its aim to raise standards, is an ideological position. The drive for authentic science is an ideological position which puts the needs of those who will potentially become scientists ahead of the majority. The need to increase the numbers of students studying sciences beyond compulsory schooling is an ideological position. That is not to say that any of these positions are right or wrong, but that they are ideologically driven.

The perceived needs of those who will continue to study science thus seem to be being foregrounded over the needs of the majority - a position decried as 'ethically dubious' (Hodson, 1993, p. 93). The drive for an increase in the numbers of students studying science, and the way such a drive can direct the objectives of the science curriculum, have been critiqued by Jenkins (2009). Indeed, science education for all students:

can only be justified if it offers something of universal value for all rather than the minority who will become future scientists. (Osborne \& Dillon, 2008, p. 7)

In the case of increasing the amount of mathematics within science, it would appear that arguments have been advanced which aim at both something of universal value for all - that of increasing students' mathematical competence - and also for the minority who will continue their study of science.

Jenkins (2009) argues that it is important to justify any arguments that are prioritised in developing curricula. The arguments for increasing the amount of mathematics within science do not appear to have been justified, at least not within the curriculum documents themselves, but are rather taken as self-evidential or common sense. As these ideologies influence the values which are operationalised in the curriculum, and the curriculum gives authority to those values, the ideologies which lie behind the curriculum should be explored and interrogated. 


\section{Acknowledgements}

With thanks to Prof Justin Dillon at the University of Exeter and Dr Heather King at King's College London.

This research was funded by the Rosalind Driver Research Scholarship Fund at King's College London.

\section{References}

Apple, M. (1993). The politics of official knowledge: Does a national curriculum make sense? Discourse: Studies in the Cultural Politics of Education, 14(1), 1-16.

ASE. (1981). ASE Policy Statement: Education through science. Hatfield: ASE.

Ball, S. (1990). Politics and policy making in education. Routledge: London.

Ball, S. (2013). The education debate (2nd ed.). Bristol: The Policy Press.

BERA. (2011). Ethical guidelines for educational research. London: BERA.

Bernstein, B. (2000). Pedagogy, symbolic control and identity (2nd ed.). Lanham, Maryland: Rowman \& Littlefield.

Bosch, M., \& Gascón, J. (2006). Twenty-five years of the didactic transposition. ICMI Bulletin, 51-65. Retrieved from https://isis.ku.dk/kurser/blob.aspx?feltid=233272

Braun, V., \& Clarke, C. (2013). Successful Qualitative Research. London: Sage.

Charmaz, K. (2006). Constructing grounded theory: A practical guide through qualitative analysis. London: Sage.

Chevallard, Y., \& Bosch, M. (2013). Didactic Transposition in mathematics education. In S. Lerman, Encyclopedia of Mathematics Education. Berlin Heidelberg: SpringerVerlag.

Clesham, R. (2013). Good Assessment by Design - an international comparative analysis of science and mathematics assessments. London: Pearson. Retrieved October 2014, from http://uk.pearson.com/content/dam/ped/pei/uk/pearsonuk/Documents/wcq/WCQ_international_comparison_paper_full_version.pdf

Cohen, L., Manion, L., \& Morrison, K. (2011). Reserach Methods in Education. Abingdon: Routledge.

Department for Education. (2013). Mathematics Programme of Study - Key Stage 3 .

Department for Education. Retrieved September 2014, from https://www.gov.uk/government/publications/national-curriculum-in-englandmathematics-programmes-of-study

Department for Education. (2013). Programme of Study for Mathematics - Key Stage 4. Department for Education. Retrieved September 2014, from https://www.gov.uk/government/publications/national-curriculum-in-englandmathematics-programmes-of-study 
Department for Education. (2014). GCE AS and A level subject content for biology, chemistry, physics and psychology. UK Government. Retrieved from https://www.gov.uk/government/collections/gce-as-and-a-level-subject-content

Department for Education. (2015). Biology, chemistry and physics GCSE subject content. London: Department for Education.

Department for Education. (2015). Combined science GCSE subject content. London: Crown Copyright. Retrieved October 2017, from https://www.gov.uk/government/uploads/system/uploads/attachment_data/file/593774 /Combined_science_GCSE_formatted.pdf

Department for Education and Skills. (2006). The STEM programme report. Retrieved July 2014, from National STEM Centre elibrary: http://www.nationalstemcentre.org.uk/res/documents/page/050110114146stem_progr amme_report_2006.pdf

Department for Education and Skills and Qualifications and Curriculum Authority. (2004). The National Curriculum. London: HMSO. Retrieved September 2014, from http://webarchive.nationalarchives.gov.uk/20130401151715/http://www.education.go v.uk/publications/eOrderingDownload/QCA-04-1374.pdf

Dodd, H., \& Bone, T. (1995). To what extent does the national curriculum for mathematics serve the needs of science? Teaching Mathematics and its applications, 14(3), 102106.

Donnelly, J. (2006). The intellectual positioning of science in the curriculum, and its relationship to reform. Journal of Curriculum Studies, 38(6), 623-640.

Fairbrother, R. (2008). The validity of the key stage 3 science tests. School science review, 89(329), 107-113.

Fensham, P. (2009). The link between policy and practice in science education: the role of research. Science Education, 93(6), 1076-1095.

Fensham, P. (2013). The science curriculum; the decline of expertise and the rise of bureaucratise. Journal of Curriculum Studies, 45(2), 152-168.

Halstead, J. M. (1996). Values and Values Education in Schools. In J. M. Halstead, \& M. J. Taylor (Eds.), Values in Education and Education in Values (pp. 3-14). London: Falmer.

Hill, D. (2001). Equality, ideology and education policy. In D. Hill, \& M. Cole (Eds.), Schooling and Equality: Fact, Concept and Policy (pp. 1-34). Kogan Page: London.

Hill, M. J. (2013). The Public Policy Process (5th ed.). New York: Pearson.

HM Treasury, Department for Education and Skills, Department for Trade and Industry. (2004). Science and Innovation Investment Framework. HMSO. Retrieved September 2014, from http://www.nationalstemcentre.org.uk/stem-programme/stem-background

HM Treasury, Department of Trade and Industry, Department for Education and Skills, Department of Health. (2006). Science and innovation investment framework: Next 
steps. London: Her Majesty's Stationery Office. Retrieved May 2015, from

http://webarchive.nationalarchives.gov.uk/+/http:/www.hm-

treasury.gov.uk/media/7/8/bud06_science_332v1.pdf

Hodgen, J., Kuchemann, D., Brown, M., \& Coe, R. (2009). Secondary students understanding of mathematics 30 years on. BERA 2009. Retrieved from

https://www.researchgate.net/profile/Dietmar_Kuechemann/publication/267374220_S econdary_students'_understanding_of_mathematics_30_years_on/links/551bd6c40cf2 fe6cbf75f124.pdf

Hodgen, J., McAlinden, M., \& Tomei, A. (2014). Mathematical transitions: a report on the mathematical and statistical needs of students undertaking undergraduate studies in various disciplines. York: Higher Education Academy. Retrieved April 2015, from https://www.heacademy.ac.uk/mathematical-transitions-report-mathematical-andstatistical-needs-students-undertaking

Hodgen, J., Pepper, D. S., \& Ruddock, G. (2010). Is the UK an Outlier? An international comparison of upper secondary mathematics education. London: Nuffield Foundation.

Hodson, D. (1993). Re-thinking Old Ways: Towards A More Critical Approach To Practical Work In School Science. Studies in Science Education, 22(1), 85-142.

Hollins, M., \& Reiss, M. (2016). A review of the school science curricula in eleven high achieving jurisdictions. The Curriculum Journal, 27(1), 80-94.

Jenkins, E. (2007). School science: A questionable construct? Journal of Curriculum Studies, $39(3), 265-282$.

Jenkins, E. (2009). Reforming school science education: a commentary on selected reports and policy documents. Studies in Science Education, 45(1), 65-92.

Jenkins, E. (2012). One small step for the science education research community? Studies in Science Education, 48(1), 123-127.

Koenig, J. (2011). A Survey of the mathematics landscape within bioscience undergraduate and postgraduate UK higher education. Leeds: UK Centre for Bioscience, Higher Education Academy. Retrieved October 2014, from http://www.bioscience.heacademy.ac.uk/ftp/reports/biomaths_landscape.pdf

Miles, M., Huberman, A. M., \& Saldaña, J. (2014). Qualitative data analysis: A methods sourcebook (3rd ed.). Thousand Oaks: Sage.

Millar, R., \& Osborne, J. (1998). Beyond 2000: Science education for the future. London: King's College London.

Morgan, B. (2011). Mind the Gap: Mathematics and the transition from A-levels to physics and engineering degrees. London: Institute of Physics. Retrieved October 2014, from http://www.iop.org/publications/iop/2011/file_51933.pdf 
NFER. (2011). The STEM cohesion programme: Final report. Department for Education. Retrieved July 2014, from https://www.gov.uk/government/uploads/system/uploads/attachment_data/file/182142 /DFE-RR147.pdf

Ofqual. (2015). GCSE subject level conditions and requirements for single science (biology, chemistry and physics). London: Department for Education. Retrieved October 2017, from https://www.gov.uk/government/uploads/system/uploads/attachment_data/file/600867 /gcse-subject-level-conditions-and-requirements-for-single-science.pdf

Ofqual. (2016). GCE subject level conditions and requirements for science (biology, chemistry, physics) and certificate requirements. Coventry: Crown Copyright. Retrieved October 2017, from https://www.gov.uk/government/uploads/system/uploads/attachment_data/file/600864 /gce-subject-level-conditions-and-requirements-for-science.pdf

Orton, T., \& Roper, T. (2000). Science and Mathematics: A relationship in need of counselling? Studies in Science Education, 35(1), 123-153.

Osborne, J. (2011). Science teaching methods: a rationale for practices. School Science Review, 93(343), 93-103.

Osborne, J. (2014). Teaching Scientific Practices: Meeting the challenge of change. Journal of Science Teacher Education, 25, 177-196.

Osborne, J., \& Dillon, J. (2008). Science Education in Europe: Critical reflections. London: Nuffield Foundation.

QCA. (2006). GCSE criteria for science 2006. Retrieved November 2016, from STEM learning: https://www.stem.org.uk/elibrary/resource/29197

QCDA. (2005). Science key stage 4. Retrieved July 2011, from http://curriculum.qcda.gov.uk/key-stages-3-and-4/subjects/key-stage4/science/index.aspx

Roberts, G. (2002). Get SET for Success: The supply of people with Science, Technology, Engineering and Mathematics skills. UK Government.

Rubin, H., \& Rubin, I. (1995). Qualitative Interviewing: The art of hearing data. Thousand Oaks, CA: Sage.

Ryder, J. (2015). Being professional: accountability and authority in teachers' responses to science curriculum reform. Studies in Science Education, 51(1), 87-120.

Ryder, J., \& Banner, I. (2011). Multiple Aims in the Development of a major reform of the National Curriclum for Science in England. International Journal of Science Education, 33(5), 709-725.

Sainsbury, D. (2007). The Race to the top. HMSO. Retrieved from http://www.nationalstemcentre.org.uk/stem-programme/stem-background 
Science and Learning Expert Group. (2010). Science and mathematics secondary education for the 21st century. London: Department for Business, Innovation and Skills.

SCORE. (2009). GCSE Science 2008 Examinations. Retrieved November 19, 2012, from Score Education: http://www.score-education.org/media/3200/score_report_final.pdf

SCORE. (2011). GCSE Science Examinations 2008, 2009, 2010 Summary Report. London: SCORE. Retrieved from http://www.scoreeducation.org/media/10927/report_gcse\%20science_2008_2010_final.pdf

SCORE. (2012). Mathematics within A-level Science 2010 examinations policy report. London: SCORE. Retrieved October 2014, from http://www.scoreeducation.org/media/10033/score\%20maths\%20in\%20science\%20summary\%20repor t.pdf

SCORE. (2014). SCORE consultation responses. Retrieved October 2017, from SCORE education: http://www.score-education.org/news/consultation-responses

Shayer, M., \& Adey, P. (1981). Towards a science of science teaching. Oxford: Heinemann.

Singh, P. (2002). Pedagogising knowledge: Bernstein's theory of the pedagogic device. British Journal of Sociology of Education, 23(4), 571-582.

Smith, A. (2004). Making Mathematics Count. London: The Stationary Office.

Smith, M. E. (2013). Independent Chair's report on the review of current GCE 'specification content' within the subject criteria. OFQUAL. Retrieved 2014 October, from http://ofqual.gov.uk/files/2013-09-06-smith-review-of-specification-content-july2013.pdf

Sturges, J., \& Hanrahan, K. (2004). Comparing Telephone and Face-to-tace Qualitative Interviewing: a research note. Qualitative Research, 4, 107-118.

The Royal Society. (2014). A Vision for science and mathematics education. London: The Royal Society. Retrieved December 2016, from https://royalsociety.org/ /media/education/policy/vision/reports/vision-full-report20140625.pdf

Walford, G. (2012). Researching the powerful in education: a reassessment of the problems. International journal of research and method in education, 35, 111-118.

Watson, A. (2008). School mathematics as a special kind of mathematics. For the learning of mathematics, 28(3), 3-7.

Wong, V. (2018). The relationship between school science and mathematics education. $\mathrm{PhD}$ Thesis, King's College London, London.

Young, M. (2011). The return to subjects: a sociological perspective on the UK Coalition government's approach to the 14-19 curriculum. The Curriculum Journal, 22(2), 265278. 
26|P a g e 